\title{
Background radiation dose-rates to non-human biota in a high mountain habitat in Norway
}

\author{
J.E. Brown ${ }^{1}$, R. Gjelsvik ${ }^{1}$, J.A. Kålås ${ }^{2}$ and P. Roos ${ }^{3}$ \\ ${ }^{1}$ Norwegian Radiation Protection Authority, PO Box 55, 1332 Østeras, Norway \\ ${ }^{2}$ Norwegian Institute for Nature Research (NINA), Tungasletta 2, 7485 Trondheim, Norway \\ ${ }^{3}$ RIS $\varnothing$-DTU, PO Box 49, 4000 Roskilde, Denmark
}

\begin{abstract}
Determination of background radiation dose-rates is important in the process of assessing risks to the environment from exposure to human activities both in terms of deriving the incremental dose-rate and as a point of reference for evaluating the significance of the exposure level. A consideration of the available literature on naturally occurring radionuclides in wild plants and animals quickly illustrates a paucity of data coverage in numerous cases. Most notable is the lack of comprehensive information for the important dose-forming radionuclides such as ${ }^{210} \mathrm{Po}$ and ${ }^{210} \mathrm{~Pb}$. In order to collate data concerning these radioisotopes for components of the ecosystem, field work was conducted in a semi-natural, mountainous location in central Norway. Preliminary (since no correction was made for ingrowth from ${ }^{210} \mathrm{~Pb}$ ) whole-body activity concentrations of ${ }^{210} \mathrm{Po}$ in 2 species of small mammal were commensurate with activity concentrations reported for reindeer muscle sampled at proximate locations, falling at a level of some $10 \mathrm{~s}$ of $\mathrm{Bq} \mathrm{kg}^{-1}$ by fresh weight. Statistical analyses of the data showed that bank vole and shrew ${ }^{210}$ Po data constitute different populations with different mean ranks. Unweighted dose-rates attributable to the presence of internally distributed ${ }^{210} \mathrm{Po}$ were calculated to be $0.07 \mu \mathrm{Gy} \mathrm{h}^{-1}$ for Bank vole.
\end{abstract}

\section{INTRODUCTION}

In recent years, there have been intensive activities on a global basis in relation to the development of methodologies for assessing impacts of ionising radiation on the environment. At a European level, the EURATOM-funded project ERICA, Environmental Risk from Ionising Contaminants: Assessment and Management [1] has proven to be a driving force in this respect. A key activity in the ERICA project was to consider the transfer of radionuclides through food-chains, irrespective of whether humans constitute a component of the food-chain or not, with special focus on provision of data for reference organisms. These organisms, representing the broader ecosystem, provide a basis for radiation dose rates estimations from a contaminated environment.

Arguably, two points of reference may be used for the purpose of assessing the potential consequences of exposures to radiation on non-human biota. These are (a) natural background dose rates and (b) dose rates known to have specific biological effects on individual organisms [2]. Bands of derived consideration levels for reference fauna and flora could be compiled by combining information on logarithmic bands of dose rates relative to normal natural background dose rates in combination with information on dose rates that may have an adverse effect on reproductive success, or result in early mortality (or cause morbidity), or are likely to result in scorable DNA damage for such organisms [3]. Such a banding would be interpreted on the basis that additions of dose rate that were only fractions of their background might be considered to be trivial or of low concern; those within the normal background range might need to be considered carefully; and those that were one, two, three or more orders of magnitude greater than background would be of increasingly serious concern because of their known adverse effects on individual fauna and flora [2].

Numerous data deficiencies have been uncovered in addressing issues related to the characterisation of background dose rates to reference organisms. However, on further inspection it becomes evident 
that some of these data deficiencies could be easily mitigated with limited effort involving field-work and analysis. The objective of this work was therefore to identify data gaps in relation to the levels and transfer of naturally occurring radionuclides in terrestrial ecosystems (with a focus on the important dose-forming radionuclides ${ }^{210} \mathrm{Po}$ and ${ }^{210} \mathrm{~Pb}$ ) and to plan and conduct a terrestrial field campaign with the purpose of filling some of these information gaps. This would facilitate the calculation of more robust background dose-rates for selected terrestrial system hitherto not studied.

Lead-210 and its granddaughter ${ }^{210} \mathrm{Po}$ are members of the ${ }^{238} \mathrm{U}$ decay series. They are formed in the atmosphere following decay via a number of intermediate short-lived radionuclides from gaseous ${ }^{222} \mathrm{Rn}$. Deposition of ${ }^{210} \mathrm{~Pb}$, associated with aerosols in the atmosphere, occurs via meso-scale transportation process, sedimentation and precipitation. In Scandinavia, the radionuclide is deposited continuously to earth at a rate of approximately $55 \mathrm{~Bq} \mathrm{~m}^{-2}$ per annum [4]. Early models concerning the atmospheric ${ }^{210} \mathrm{~Pb}$ transport were based on the vertical movement of the radioisotope into the troposphere at the equator followed by lateral movement to mid-latitudes and deposition, whereas more recent, refined models have included regional sources of ${ }^{222} \mathrm{Rn}$ to account more robustly for the ${ }^{210} \mathrm{~Pb}$ deposition rates observed across the major continents (see [5]). Atmospheric ${ }^{210} \mathrm{~Pb}$ concentrations are positively correlated with the size of the underlying landmasses, whereas terrestrial areas covered by ice and snow and marine areas including islands have reduced atmospheric concentrations of ${ }^{210} \mathrm{~Pb}$ [4]. Furthermore, the deposition of ${ }^{210} \mathrm{~Pb}$ is directly correlated with the level of precipitation [6].

For mountainous areas dominated by Alpine vegetation, lichen appears to play a key role in the introduction of ${ }^{210} \mathrm{~Pb}$ into the foodchain. Lichens are slow growing perennials that have high interception potentials for aerosols in precipitation, and therefore contain significantly higher ${ }^{210} \mathrm{~Pb}$ concentrations than vascular plants [7]. Animals feeding on lichens, notably reindeer, have been shown to have relatively high muscle and organ ${ }^{210} \mathrm{Po}$ and ${ }^{210} \mathrm{~Pb}$ activity concentrations [7]. For animals not feeding on lichen, entry of ${ }^{210} \mathrm{~Pb}$ and ${ }^{210} \mathrm{Po}$ into the foodchain presumably primarily occurs through the ingestion of vegetation (with relatively low concomitant activity concentrations relative to lichen), dust and soil.

\section{IDENTIFICATION OF KNOWLEDGE GAPS}

The empirical data coverage (Concentration ratios, CRs, and thereby activity concentrations in plants and animals) for selected radionuclides provided by the ERICA project for terrestrial environments is presented by Beresford et al. [8]. The coverage for $\mathrm{Pb}$ was found to be reasonable, presumably reflecting the large number of stable element studies that have been conducted on this element. Other radioelements were more poorly characterised with empirical data sets. In the case of Polonioum, some information was available for flora but only for the fauna group mammals. In the latter case it should be noted that although tens of data values are available these represent "all mammals" from a single geographical area - the UK. Although numerous data exist for reindeer, these data were excluded in the work of Beresford et al. [8] as the air-lichen-reindeer pathway was considered unlikely to be representative of contamination routes for other terrestrial mammals and was therefore likely to result in over predictions for the mammal reference organism category. The number of values associated with Thorium was found to be low. In all cases the number of available empirical values was below 20 and for 7 reference categories no information was available at all. A similar situation existed for Uranium although, arguably, floral reference organisms were characterised by reasonable CR information. For radium there were severe data deficiencies for invertebrates, insects, amphibia and reptiles.

The Environment Agency of England and Wales recently commissioned work to develop databases to underpin environmental impact assessment using reference animals and plants [9]. ICRPs Reference Animal or Plant (RAP) are defined as "a hypothetical entity, with assumed basic characteristics of a specific type of animal or plant, as described to the generality of the taxonomic level of the Family, with precisely defined anatomical, physiological and life history properties that can be used for the purposes of relating exposure to dose and dose to effects for that type of living organism" [10]. In considering an overview of these data, there were no data for some Reference animals and plants, notably frog, bee, 
earthworm and rat and very few data for some other groups, notably duck $\left({ }^{40} \mathrm{~K}\right.$ only) and deer $\left({ }^{40} \mathrm{~K}\right.$, 1 data point for $\left.{ }^{210} \mathrm{Po}\right)$. In order to address this numerous samples were measured predominately for $\mathrm{U}$ and Th. New data were generated for, inter alia, ducks, trout and insects thus providing some new information to fill data gaps albeit specifically for the UK environment. However, no new measurements of ${ }^{210} \mathrm{Po}$ were made in the study. An overview of data availability for UK biota based on a literature review [9] is presented in Table 1.

Table 1. Observations of ${ }^{232} \mathrm{Th}$ and ${ }^{238} \mathrm{U}$ decay series radionuclides from [9].

\begin{tabular}{|l|ccccccc|}
\hline & Po-210 & Pb-210 & Ra-226 & Th-230 & Th-232 & U-234 & U-238 \\
\hline Duck & no data & no data & no data & $\mathrm{N} \leqslant 10$ & $\mathrm{~N} \leqslant 10$ & no data & no data \\
Pine tree & $\mathrm{N} \leqslant 10$ & $\mathrm{~N} \leqslant 10$ & $\mathrm{~N} \leqslant 10$ & $\mathrm{~N} \leqslant 10$ & $\mathrm{~N} \leqslant 10$ & $\mathrm{~N} \leqslant 10$ & $\mathrm{~N} \leqslant 10$ \\
Wild grass & $\mathrm{N}>10$ & $\mathrm{~N}>10$ & $\mathrm{~N}>10$ & $\mathrm{~N} \leqslant 10$ & $\mathrm{~N}>10$ & $\mathrm{~N}>10$ & $\mathrm{~N}>10$ \\
All mammals & $\mathrm{N}>10$ & $\mathrm{~N}>10$ & no data & $\mathrm{N} \leqslant 10$ & $\mathrm{~N}>10$ & $\mathrm{~N} \leqslant 10$ & $\mathrm{~N} \leqslant 10$ \\
Deer & $\mathrm{N} \leqslant 10$ & no data & no data & no data & no data & no data & no data \\
\hline
\end{tabular}

\section{FIELD CAMPAIGN}

A field study was planned and implemented at Dovre, Central part of Norway $\left(62^{\circ} 17^{\prime} \mathrm{N}, 9^{\circ} 36^{\prime} \mathrm{E}\right)$ during the period $17-20^{\text {th }}$ June 2007 . The field study was conducted within a designated Landscapeprotected area near to Kongsvold adjacent to Dovrefjell-Sunndalsfjella National Park. This study site was selected primarily on the basis that it forms part of the network for Monitoring programme for Terrestrial Ecosystems (TOV) in Norway, led by the Norwegian Institute for Nature Research (NINA), and concerning, inter alia, effects of pollution on plants and animals and chemical and biological monitoring. In this way, a large dataset of ancillary information would be available facilitating any subsequent interpretation of results. Furthermore, by connecting this field programme to ongoing studies, associated costs could be reduced.

Eight soil profiles were collected during the field expedition. These profiles were split into an overlying humus layer and thereafter $3 \mathrm{~cm}$ (predominantly mineral soil) increments to a depth of $9 \mathrm{~cm}$ using a custom-designed soil corer. This was undertaken with a view to enabling analyses of the activity distribution of radionuclides with depth. Baited traps were used in the collection of various small mammals including Bank Vole (Clethrionomys glareolus) and the Common Shrew (Sorex araneus). Plant samples including samples of bilberry (Vaccinium myrtillus) and 2 species of lichens (e.g. Cladonia stellaris and Cladonia arbuscula) were collected by hand. Finally, samples of two earthworm species (Lumbricus rubellus and Aportectodea caliginosa) were collected in areas of brown earth using a spade.

A detailed description of the analysis of polonium in the samples is given in Chen et al. [11]. Briefly, the freeze-dried material (2-10 g) was added to a semi-closed glass flask, ${ }^{208} \mathrm{Po}$ and a known amount of stable $\mathrm{Pb}(5-10 \mathrm{mg})$ added as yield determinants for ${ }^{210} \mathrm{Po}$ and ${ }^{210} \mathrm{~Pb}$ respectively. The sample was completely dissolved using a mixture of $\mathrm{HNO}_{3}, \mathrm{HCl}$ and $\mathrm{H}_{2} \mathrm{O}_{2}$, evaporated to near dryness and polonium plated onto silver discs in a weak hydrochloric solution. The discs were then analysed without delay using solid state PIPS-detectors. The solution remaining after plating onto the Ag-discs were rinsed from remaining traces of polonium using TIOA-extraction in $10 \mathrm{M} \mathrm{HCl}$. The aqueous phase containing $\mathrm{Pb}$ was set aside for ${ }^{210} \mathrm{Po}$ ingrowth.

\section{RESULTS AND DISCUSSION}

Only preliminary data for small mammals were available at the time of writing of this paper. When deriving activity concentrations of ${ }^{210} \mathrm{Po}$ for the time of sampling, a simple decay correction procedure cannot be used because the ${ }^{210} \mathrm{Po}$ attributable to the whole body of the samples at the time of analysis 


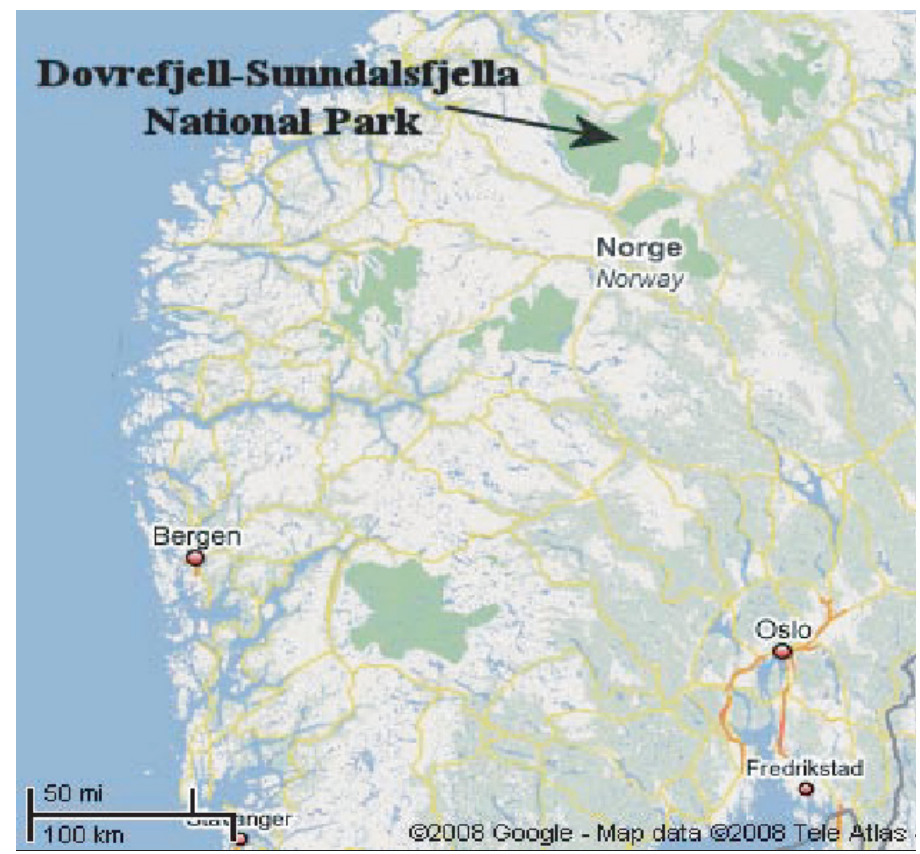

Figure 1. Sampling location - Dovrefjell-Sunndalsfjella National Park.

is likely to be comprised of activity remaining from the decay of unsupported ${ }^{210} \mathrm{Po}$ and a component arising from ingrowth via ${ }^{210} \mathrm{~Pb}$ (between the time of sampling and the time of analysis). Essentially, we can assume that some ${ }^{210} \mathrm{~Pb}$ is present in the samples (organs within the body such as the liver are known to accumulate stable and therefore radioactive lead) and that the in situ decay of this radioisotope is contributing to the activity measured at the time of analysis.

Since only ${ }^{210}$ Po results were available at the time of writing of this paper, the results reported here (provisionally decay corrected to date of sampling) are of a preliminary nature only. Once the level of ${ }^{210} \mathrm{~Pb}$ has been determined for the samples, the unsupported activity concentration for ${ }^{210} \mathrm{Po}$ at the time of sampling can be determined precisely.

The preliminary data exhibit activity concentrations in the range $41-88 \mathrm{~Bq} \mathrm{~kg}^{-1} \mathrm{~d} . \mathrm{w}$. for bank vole ${ }^{210} \mathrm{Po}$ and $22-84 \mathrm{~Bq} \mathrm{~kg}^{-1}$ d.w. ${ }^{210} \mathrm{Po}$ for the common shrew (Fig. 1). The non-parametric Mann-Whitney test has been applied in order to determine whether data ${ }^{210} \mathrm{Po}$ activity concentrations in shrew are statistically different to corresponding data for bank vole. The null hypothesis is that these 2 samples have been taken from a common population so that there is no consistent difference between the 2 sets of data. Since there is no hypothesis concerning whether the mean rank of one population is greater or less than the other, a two tailed test was considered appropriate.

Median activity concentrations of ${ }^{210} \mathrm{Po}$ in bank vole $\left(74 \mathrm{~Bq} \mathrm{~kg}^{-1}\right.$ d.w.) appear to be significantly different to those determined for shrew $\left(30 \mathrm{~Bq} \mathrm{~kg}^{-1} \mathrm{~d}\right.$.w.). This is confirmed by the fact that the null hypothesis can be rejected at the $\mathrm{p}<0.008$ level, i.e. the probability that the 2 sets of data come from the same population is extremely low and it is reasonable to conclude that bank vole and shrew ${ }^{210} \mathrm{Po}$ data constitute different populations with different mean ranks.

Bank voles have a broad diet, which is mainly herbivorous, including fruit, soft seeds, leaves, fungi, roots, grass, buds and moss. They may also occasionally take invertebrate food such as snails, worms and insects may be eaten. The common shrew feeds on most terrestrial insects, but will also take worms, slugs and snails. The statistical tests undertaken in this study appear to highlight the importance of 


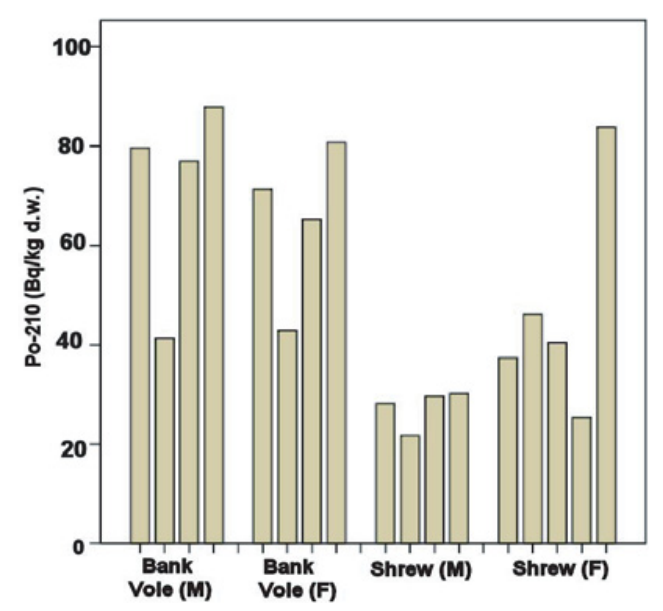

Figure 2. Po-210 activity concentrations in bank vole and common shrew. $\mathrm{M}=$ male and $\mathrm{F}=$ Female.

diet in terms of influence on body burdens of ${ }^{210} \mathrm{Po}$. It appears that the primarily herbivorous bank vole is accumulating higher concentrations of these natural radionuclides compared to the insectivorous shrew. Because the metabolic rate of these small mammals is expected to be fairly similar, relative to poikilotherms of similar size or homeotherms of different sizes, it may be hypothesized that the biological half-lives for ${ }^{210} \mathrm{Po}$ in shrew and bank vole are also quite similar. If this holds true, the activity concentration of ${ }^{210} \mathrm{Po}$ in the food consumed by these small mammals would appear to be driving the differences observed.

The ${ }^{210}$ Po activity concentrations for the whole body of the bank vole and shrew are similar in magnitude to activity concentrations determined for the muscle of reindeer, sampled at a site $<100 \mathrm{~km}$ distant at Vågå in Norway. At this location activity concentrations of $36 \mathrm{~Bq} \mathrm{~kg}^{-1} \mathrm{~d}$.w. in female reindeer muscle and several hundred $\mathrm{Bq} \mathrm{kg}^{-1} \mathrm{~d}$.w. in liver were determined [7].

The dry mass to fresh mass ratio was on average 0.3 . This suggests median activity concentrations by fresh mass of approximately $22 \mathrm{~Bq} \mathrm{~kg}^{-1} \mathrm{f}$.w. on average for Bank Vole and $9 \mathrm{~Bq} \mathrm{~kg}^{-1} \mathrm{f}$.w. for the Common shrew, albeit that these are preliminary determinations. These activity concentrations are considerably higher than the levels reported in [9] where an activity concentration of $0.09 \mathrm{~Bq} \mathrm{~kg}^{-1}$ f.w. was reported for a category consigned the title "All mammals" and comprising of 32 assorted samples. Whether this discrepancy reflects the preliminary nature of the results presented in this paper, differences (physiology, diet, habitat) between the mammals considered in the aforementioned study and the present study or differences in deposition of ${ }^{210} \mathrm{~Pb}$ between the study areas, remains a subject for further investigation.

Unweighted dose-rates have been derived using the dose assessment methodology described by Brown et al. [12]. No alpha radiation weighting factor has been applied because international consensus on the magnitude of this value has not been attained despite the consideration of such values in the open literature (see [13]). Background radiation dose rates to Bank Vole (whole-body) attributable to the presence of internally distributed ${ }^{210}$ Po were calculated to be $0.07 \mu \mathrm{Gy} \mathrm{h}^{-1}$.

\section{Acknowledgments}

This work was supported by the Nordic Nuclear Safety Research (NKS) and forms part of the GAPRAD (Filling knowledge gaps in radiation protection methodologies for non-human biota) project (NKS Order [AFT/B(07)8]). The financial support of the NKS is gratefully acknowledged. The authors also thank The Direktoratet for naturforvaltning and Oppdal Kommune for giving permission to sample small mammals in the study area. 


\section{References}

[1] C.-M. Larsson, An overview of the ERICA Integrated Approach to the assessment and management of environmental risks from ionising contaminants. Journal of Environmental Radioactivity (in press).

[2] R.J. Pentreath, Journal of Radiological Protection, 22, 45-56 (2002).

[3] ICRP, Annals of the ICRP, 91, 201-266 (2003).

[4] F. El-Daoushy, Environ. Int. 14, 305-319 (1988).

[5] C.R. Macdonald, L.L. Ewing, B.T. Elkin, A.M. Wiewel, Sci. Total Environ. 182, 53-73 (1996).

[6] Hill, C.R., Nature, 187, 211-212 (1960).

[7] L. Skuterud, J.P. Gwynn, E. Gaare, E. Steinnes, K. Hove, Journal of Environmental Radioactivity, 84, 441-456 (2005).

[8] N.A. Beresford, C.L. Barnett, B.J. Howard, W.A. Scott, J.E. Brown, D. Copplestone, Derivation of transfer parameters for use within the ERICA Tool and the default concentration ratios for terrestrial biota. Journal of Environmental Radioactivity (in press).

[9] N.A. Beresford, J.D. Appleton, C.L. Barnett, M.W. Bescoby, N. Breward, D.G. Jones, A.C. MacKenzie, C. Scheib, M.D. Wood, H. Thørring (2007). Assessment of naturally occurring radionuclides around England and Wales. Project SC030283. Environment Agency, Bristol. pp. 79.ISBN:1844325679. Availablefrom: http://www.ceh.ac.uk/protect/pages/documents/Assess mentofnaturallyoccurringradionuclidesinEnglandandWales.pdf

[10] ICRP, Annals of the ICRP (Volume) 37/2-4, 133-135 (2007).

[11] Chen, Q., Aarkrog, A., Nielsen, S.P., Dahlgaard, H., Lind, B., Kolstad, A.K., Yu, Y. (2001). Procedures for Determination of ${ }^{239,240} \mathrm{Pu},{ }^{241} \mathrm{Pu},{ }^{237} \mathrm{~Np},{ }^{234,238} \mathrm{U},{ }^{228,230,232} \mathrm{Th},{ }^{99} \mathrm{Tc}$, and ${ }^{210} \mathrm{~Pb}$ ${ }^{210}$ Po in Environmental Materials. RIS $\varnothing$ report, Ris-r-1263.

[12] J.E. Brown, B. Alfonso, R. Avila, N.A. Beresford, D. Copplestone, G. Pröhl, A. Ulanovsky, The ERICA Assessment Tool. Journal of Environmental Radioactivity (in press).

[13] D.B. Chambers, R.V. Osborne, A.L. Garva, Journal of Environmental Radioactivity, 87, 1-14 (2006). 